\title{
As empresas e seus valores: análise das declarações de
} valores das maiores empresas brasileiras

\author{
ANDRÉ REHBEIN SATHLER ${ }^{1}$ \\ ROBERTO CAMPOS ROCHA MIRANDA ${ }^{2}$ \\ MURILO DE ASSIS SILVA ' \\ ${ }^{1}$ Centro Universitário IESB / Escola de Negócios, Brasília - DF, Brasil \\ ${ }^{2}$ Centro de Formação, Treinamento e Aperfeiçoamento da Câmara dos \\ Deputados, Brasília - DF, Brasil
}

\begin{abstract}
Resumo
O objetivo da pesquisa é traçar um perfil identitário das maiores empresas brasileiras com base na análise de suas declarações de valores. A estratégia foi qualitativa, com uso de técnicas de análise de conteúdo e de discurso, bem como software específico (Iramuteq). Os resultados indicaram que a maioria das empresas ostenta uma declaração de visão em seus sites (62,2\%). Há uma média de 5,82 valores por empresa, similar à internacional. Os elementos semânticos mais predominantes sinalizam para uma dupla preocupação: ética e inovação. Os resultados demonstram que a técnica de elaboração e o uso de declarações de valores estão bem difundidos e aceitos no Brasil, inclusive apontando para declarações mais extensas de valores das empresas nacionais. $\mathrm{O}$ artigo identifica lacunas que sugerem estudos futuros, como a análise da aderência das pessoas aos valores organizacionais e a especificidade das empresas brasileiras em relação às internacionais. Palavras-chave: Gestão estratégica declarações de valores. Discurso de gestão. Análise de conteúdo.
\end{abstract}




\title{
Companies and its values: an analysis of spoused values of Brazilian bigger companies
}

\begin{abstract}
The research aim to delineate an identity profile of the 500 bigger Brazilian's companies, from their espoused values. The research strategy is qualitative, using content analysis and discourse analysis techniques and the software Iramuteq. The results show that the majority of Brazilian's companies do have espoused values in their home pages $(62.2 \%)$. There is an average of 5.82 values per company, similar to the international average. The semantic elements more prevalent points to a double concern: ethics and innovation. The results show that the technique of elaborating and using espoused values is well spread in Brazil, and points to a higher creativity of Brazilian companies in defining values. The paper identifies new possibilities for studies, as the adhesion of employees to the organizational values and for the differences between Brazilian and international companies.

KeYwords: Strategic management. Value statements. Management discourse. Content analysis.
\end{abstract}

\section{Empresas y sus valores estratégicos: un análisis de los valores estratégicos de las empresas más grandes de Brasil}

\section{Resumen}

El objetivo de la investigación fue dibujar un perfil de identidad de las compañías brasileñas más grandes, basado en el análisis de sus declaraciones de valor. La estrategia de investigación es cualitativa, utilizando técnicas de análisis de contenido y análisis del discurso, así como software específico (Iramuteq). Los resultados indican que la mayoría de las empresas tienen una declaración de visión en sus sitios de Internet (62,2\%). Existe una media de 5,82 valores por empresa, similar al internacional. Los elementos semánticos más predominantes apuntan a una doble preocupación: la ética y la innovación. Los resultados demuestran que la técnica de elaboración y uso de las declaraciones de valor están bien difundidas y aceptadas en Brasil, existiendo una creatividad nacional en la explicación de los valores. El artículo identifica las brechas que sugieren estudios futuros, como el análisis de la adhesión de las personas a los valores organizacionales y la especificidad de las empresas brasileñas en relación con las internacionales.

Palabras clave: Gestión estratégica. Declaraciones de valores. Discurso de gestión. Análisis de contenido. 


\section{INTRODUÇÃO}

O objetivo da pesquisa é traçar um perfil identitário das maiores empresas brasileiras com base na análise de seus valores assumidos e comunicados em declaração formal. O tema é abordado pelos campos da cultura e do comportamento organizacional, embora faça parte também de estudos de estratégia competitiva. Em particular, foram estudadas declarações explícitas e formais de valores - que passaremos a identificar como DV -, considerando-as como expressões discursivas, autodeclarativas, quanto à identidade das organizações, com reflexos, desejados ou esperados, sobre seus fazeres.

A pesquisa sobre valores corporativos ganhou fôlego com seu reconhecimento como base para compreensão de prioridades e crenças fundamentais das organizações, ou seja, como um elemento crítico para analisar as formas como as organizações lidam com a necessidade de coesão e coerência em seu funcionamento. Agle e Caldwell (1999) mostraram diversos Chief Executive Officers (CEOs) - o equivalente no Brasil a presidente ou diretor-geral das empresas - que afirmam, de modo taxativo, a importância dos valores para as empresas que dirigiam. Esses autores também defendem que os princípios são determinantes de quase todos os tipos de comportamento social, inclusive o estratégico, para o qual são prescritores fundamentais. Há uma extensa literatura sobre valores corporativos em inglês, mas não há o mesmo nível de interesse na literatura em português. Em especial, o enfoque dado pela presente pesquisa, o de analisar as DV em si, não foi encontrado na literatura nacional.

Assim, o presente texto visa contribuir para o preenchimento de algumas lacunas. A primeira se refere à possibilidade de descrever o estado da arte da questão no contexto das quinhentas maiores empresas brasileiras - quais delas apresentam uma DV em seus sítios de internet e como estão formulados. De forma indireta, esse levantamento funciona como indicador da absorção da literatura sobre valores corporativos em termos práticos pelo conjunto das maiores empresas nacionais. A segunda se refere ao aspecto formal das DV em língua portuguesa como são redigidas, principais marcadores e descritores utilizados. Por fim, uma terceira lacuna está na falta de análise de DV em português.

Como referência principal, optou-se pelo trabalho de Bourne, Jenkins e Parry (2017), que conduziram pesquisa de perfil semelhante no universo empresarial norte-americano. Foram utilizadas técnicas de análise de conteúdo e de discurso, com recurso do software Iramuteq. Tratase de tarefa ampla e ensejadora de várias pesquisas interdependentes. A opção inicial, portanto, foi pela abordagem exploratória, com vistas a delimitar o campo para pesquisas futuras.

O exame é fruto de projeto de pesquisa sobre comportamento organizacional, desenvolvido no programa de mestrado em gestão estratégica das organizações do Centro Universitário Iesb, em Brasília.

\section{Valores corporativos: ideal, marketing ou hipocrisia?}

\section{Valores corporativos: definições}

Valores corporativos já foram pesquisados com vários enfoques. Sua relação com o desempenho organizacional foi analisada por Nohria e Ghoshal (1994), Hambrick e Brandon (1988), Deal e Kennedy (1982), Peters e Waterman Junior (1982), além de Enz (1989). A 
relação entre valores e comportamento organizacional foi estudada por Amis, Slack e Hinings (2002), Hofstede (1997, 1976), Posner e Schmidt (1992), England e Lee (1974). No âmbito da psicologia organizacional e da cultura organizacional, a relevância dos valores foi estudada por Pettigrew (1987), Meyerson e Martin (1987), Schein (1985), Bartunek (1984), Ranson, Hinings e Greenwood (1980). Grojean, Resick, Dickson et al. (2004) fizeram uma interessante análise do papel dos valores na produção de um clima organizacional ético dentro das empresas, corroborado por Dickson, Smith, Grojean et al. (2001), Victor e Cullen (1987), Schneider (1975) e Lee (1986). Mais recentemente, os valores organizacionais têm sido pesquisados quanto à sua relação com outras áreas da administração, como mudança (BURNES e JACKSON, 2011), liderança (CHA e EDMONDSON, 2006; STADLER e HINTERHUBER, 2005) e estratégia (CARLISLE e BADEN-FULLER, 2004; BANSAL, 2003). Os trabalhos foram identificados pela pesquisa bibliométrica utilizando o Portal de Periódicos da Capes e o Google Scholar.

Quando o funcionário ingressa na empresa, encontra um ideário coletivo já existente. Valores podem ter extrema generalidade e abstração, em contraste com os manuais operacionais, cujo conteúdo é sempre mais concreto e preciso. São uma tradução discursiva dos fundadores ou donos e, posteriormente, do próprio grupo ao longo do tempo, representando um ideal transcendente em relação à realidade. Ou seja, os valores não são pensados ou expressados como pontos de referência para determinado agir específico, de forma rígida e absoluta. Antes, são polissêmicos e requerem a compreensão da riqueza de seus significados, funcionando como uma consciência coletiva, mas particularizada. Em termos filosóficos, referem-se mais a como as coisas devem ser do que a como são na realidade.

Valores são elementos identitários das corporações, pois contribuem para sua personalidade, cultura e clima organizacional, afetando o funcionamento e o relacionamento interno e externo corporis. A PepsiCo é diferente da Coca-Cola, ainda que ambas sejam empresas que atuam no mesmo setor e com produtos similares. Os valores são normas de conteúdo axiológico, cujo sentido é dado em confronto com os contextos. Valores são realidade social e definem um espaço social, criando conexões de significados. Adaptando-se a eles, as pessoas denotam uma estilização alterdirigida de si mesmas, o tipo de subjetividade que responde à lógica da cultura organizacional das empresas.

De um ponto de vista institucionalista, assumindo as organizações como sistemas sociais, tem-se que objetivos e procedimentos tendem a alcançar um status impregnado de valor (SELZNIK, 1949). Com base nesse insight, o papel dos valores organizacionais na estruturação da organização passou a ser estudado de forma mais ampla. Segundo a perspectiva institucionalista, as chances de sobrevivência de uma organização aumentam muito com demonstrações de conformidade entre o ambiente institucional e os valores (congruência), aspecto destacado por Meyer e Rowan (1977). Ainda segundo essa linha de pesquisa, o grande público avalia as empresas pelo grau em que as características estruturais e procedurais estejam alinhadas com os valores institucionais preconizados (BAUM e OLIVER, 1991). Ou seja, a população em geral e os reguladores em particular seriam sensíveis à hipocrisia institucional.

Pesquisar sobre os valores adotados pelas empresas implica, num primeiro momento, ter a possibilidade de verificar um elemento autoconstruído de identidade corporativa, ou 
seja, compreender como as empresas enxergam a si mesmas do ponto de vista de valores. O levantamento do tipo censitário - busca por DVs em todas as 500 maiores empresas nacionais - possibilitou, numa primeira análise, traçar esse panorama.

\section{Valores corporativos: finalidades}

Os valores vão promover um sistema interpretativo que permite a tradução dos fatos que acontecem na empresa, indicando apenas as circunstâncias nas quais uma atuação, uma disposição psicológica ou um caráter são efetivamente designados como bons, isto é, como eticamente valiosos - estão alinhados ao pretendido dever ser. Segundo Liedtka, os valores desempenham papel semelhante ao do esquema em termos da psicologia cognitiva. Os esquemas são "estruturas de dados na memória que representam conhecimento sobre conceitos" (1991, p. 544), e os valores seriam similares scripts predeterminados nos quais as pessoas podem se apoiar para guiar o próprio comportamento. Assim, os valores qualificam certas condutas como positivas ou negativas, e é nesse sentido que se fala em realizar juízos de valor (KELSEN, 1987). Dessa forma, valores são indutores de condutas.

Embutida na pesquisa dos valores como elemento organizacional está uma concepção orgânica da empresa. Essa concepção é o mais forte e decisivo contraste com o conceito organizativo ou burocrático de instituição. Os funcionários não "fazem" uma empresa; eles "são" a empresa. Só à medida que ela, mediante os próprios princípios e valores, penetra o ser das pessoas, para além do que elas fazem, é que estas se tornam a empresa e a empresa passa a estar nelas. Os valores são um dos instrumentos que propiciam esse processo de interpenetrabilidade.

Como uma tecnologia de governo das condutas, os valores se conectam com o campo do comportamento organizacional. Como todo poder de conduzir, os valores se caracterizam pela necessidade de orientar a conduta de terceiros para metas ou lugares predefinidos, que, em princípio, devem ser o melhor para a empresa. O objetivo dos valores é conseguir orientar o comportamento coletivo dos funcionários para o bem da instituição, de forma não intrusiva e não coerciva. Por não exercerem papel de dominação impositiva, mas induzirem adesão voluntária, os valores podem ser definidos como um softpower no ambiente organizacional - quando são de fato assumidos e vivenciados pelos funcionários, acabam inevitavelmente atuando como instâncias para a conduta, às quais se pode recorrer. Essa é a verdadeira substância do valor. A cultura e os valores organizacionais são o contexto moral no qual os pensamentos individuais dos funcionários se desenvolvem e tecem pequenas variações valores podem se alterar ao longo do tempo. Os valores condicionam sem determinar a ação das pessoas, ao lhes proporcionar um sistema de significação que permite a manutenção de sua coesão psicocomportamental - diálogo de seus valores pessoais com os do grupo como elemento definidor de sua relação com o mundo.

A existência de valores, fator ainda mais acentuado diante da existência de uma DV, reduz o leque de comportamentos disponíveis e, por consequência, aumenta a previsibilidade. Sua importância no processo de gestão de pessoas se torna evidente. Ao reduzir a variedade de escolhas a serem feitas pelo funcionário, consegue-se afunilar os resultados comportamentais 
sem, explicitamente, sacrificar a liberdade de ação. Rapoport (1980) e Etzioni (1961) destacam essa dimensão de aumento da previsibilidade como um aspecto de elevação de controle dentro das organizações. Para Etzioni, o elemento que caracteriza toda a organização é o controle que dentro dela se exerce sob formas e características diversas, de acordo com a relação entre as modalidades de articulação da autoridade da organização e a expectativa dos que dela participam. Na sua perspectiva, os valores são compreendidos como um tipo de controle normativo-discursivo.

Comoumacontecimento desejado, umvalortem uma característicademetacomportamental - o fato de $x$ valorizar $y$ significa que $x$ age de modo a ocasionar a consumação de $y$. No âmbito empresarial, dado o caráter intersubjetivo dos valores (valores compartilhados), a conduta das pessoas que participam ativamente na formação e na distribuição do valor é essencial para sua possessão (usufruto). Kaplan e Laswell (1979, p. 46) ressaltam esse caráter discursivo dos valores: "Um índice dos valores de um grupo são as declarações explícitas feitas por seus membros", o que os autores denominaram de agregado reivindicatório. A probabilidade de que a comunidade de funcionários da empresa venha a se identificar umas com as outras varia com o número e a intensidade das reivindicações compartilhadas (KAPLAN e LASWELL, 1979, p. 49), o que justifica a avaliação quantitativa dos valores por empresa, feitas por Bourne, Jenkins e Parry (2017) e também na presente pesquisa. Portanto, valores são expectativas em relação às quais há um envolvimento emocional considerável das pessoas (KAPLAN e LASSWELL, 1979).

A pesquisa aponta para o tipo de valores adotados pelas empresas brasileiras em termos de conteúdo semântico, apreendido por meio de análise de conteúdo. A autoimagem do coletivo empresarial apresenta ao público, numa primeira camada, a forma como as empresas desejam ser vistas. Para o público externo, os valores escolhidos e arrolados nas DVs sinalizam os princípios éticos e valorativos com os quais as empresas estão comprometidas, permitindo qualificar a escolha do público consumidor e o posicionamento dos diversos stakeholders órgãos reguladores, fornecedores etc. Para o público interno, conforme argumentado, as DVs delineiam um conjunto de comportamentos aceitáveis e desejáveis, servindo como elemento orientador aos funcionários, individual e coletivamente.

\section{Valores corporativos e cultura organizacional}

Os valores também dialogam com as teorias de cultura organizacional, podendo ser qualificados como um dos artefatos culturais. A continuidade propiciada pelos valores compartilhados ajuda as pessoas a se compreenderem como parte de um todo que transcende os limites de sua subjetividade. Assim, os valores auxiliam a criar a ilusão de que somos maiores e mais poderosos do que na realidade somos, conforme argumentado por Morgan (1996).

Qualquer grupo, para funcionar bem, precisa de relacionamentos de confiança e reciprocidade, com as pessoas podendo enxergar em seus colegas aliados potenciais, desejando ajudar e merecendo ajuda quando necessária. Encontramo-nos aqui no campo do capital social e, uma vez que os valores contribuem para a definição do contexto dos relacionamentos, podemos colocá-los como parte do capital social. Grojean, Resick, Dickson 
et al. (2004) ressaltam que os valores facilitam interações eficientes entre os indivíduos, favorecendo, por consequência, a sobrevivência e a prosperidade da empresa. Eles criam um senso de pertença, com os sentimentos derivados de segurança e dignidade, que contribuem para dar sentido à vida. A vigência dos valores se baseia na convicção de sua legitimidade, mais do que em pretensa propaganda axiológica, o que motiva uma série de pesquisas sobre adesão das pessoas aos valores organizacionais e congruência entre os pessoais e os organizacionais.

Uma vez que, a priori, os valores são estabelecidos de um ponto de vista externo às pessoas, são também aceitos sob uma perspectiva impessoal, aplicando-se não somente ao ponto de vista do sujeito, mas também a todos de forma geral - os valores sinalizam como a pessoa deve se comportar, já que, na verdade, dizem como todos dentro da empresa devem se comportar, argumento desenvolvido com base em Nagel (2004). Assim, os valores expressam a vontade objetiva. Grojean, Resick, Dickson et al. (2004) afirmam os valores como padrões de conduta ética e moral que devem guiar o comportamento dos membros da organização, dando o que os autores chamaram de "tom ético de uma organização" (ethical tone of an organization).

Do ponto de vista da gestão empresarial, o que a alta administração pode esperar com a concepção de uma DV é alcançar um conjunto de juízos normativos, dotados de conteúdo motivacional, sob um ponto de vista impessoal. O tema central é facilitar o raciocínio prático do funcionário no processo de justificação de sua ação, uma vez que esse tenha expandido sua consciência pela adoção do viés objetivo. Aqui reside uma relação da pesquisa sobre valores com o campo da ética, pois "o pensamento ético é o processo de levar a objetividade a influenciar à vontade" (NAGEL, 2004, p. 226). A questão central para o funcionário, em sua razão prática, deixa de ser o que farei? para ser o que devo fazer?. Ainda nessa vertente da relação entre os estudos sobre valores e o campo da ética, vale lembrar Habermas (2003), que postula que os valores necessitam expressar preferências tidas como dignas de serem desejadas em determinada coletividade, podendo ser adquiridas ou realizadas por meio de um agir direcionado a um fim.

A presente pesquisa trabalhará com declarações explícitas de valores (DV), em sintonia com Bourne, Jenkins e Parry (2017), com o propósito de comparabilidade com os resultados daquela pesquisa, realizada com empresas norte-americanas e britânicas. Pretendeu-se replicar, em algumas dimensões, a pesquisa feita por Bourne, Jenkins e Parry (2017), por conta de essa discussão ter acontecido, de forma concentrada, nos Estados Unidos, nas décadas de 1980 e 1990. Naquele país, depois a discussão avançou para temas correlatos. O levantamento bibliométrico feito revela que esse tipo de pesquisa e discussão não aconteceu no Brasil, com foco em DVs em português, o que é um dos motivadores da pesquisa.

Em inglês, Bourne, Jenkins e Parry (2017) tratam como espoused values, que pode ser traduzido como valores assumidos, mas também como valores desposados, uma perspectiva interessante. As DV, em tese, devem funcionar como base para a atividade organizacional. Um ponto positivo dessa abordagem é que se pode assumir como valores organizacionais aquilo que as empresas dizem que são seus valores organizacionais, evitando-se pesquisas etnográficas complexas para uma averiguação de quais seriam, de fato, os valores da empresa. Segundo Bourne, Jenkins e Parry (2017, p. 2) “os valores assumidos têm um papel significativo 
ao representar a intenção da organização de operar de determinada forma e de encorajar comportamentos particulares por parte dos membros da organização".

Da mesma forma que a pesquisa sobre valores é ampla, conforme já demonstrado, aquelas sobre DV também têm abrangido vários recortes e são mais recentes, demonstrando um crescente interesse do campo pelo tema. Grøgaard e Colman (2016) analisaram o papel das DV na integração social dentro das empresas; Zander, Jonsen e Mockaitis (2016) pesquisaram a relação entre DV e normas culturais; Jonsen, Galunic, Weeks et al. (2015) associaram DV à performance organizacional; Howell, Kirk-Brown e Cooper (2012) investigaram a relação entre DV e comprometimento organizacional.

Bourne, Jenkins e Parry (2017) ressalvam que a pesquisa com DV pode implicar um tipo de enviesamento, uma vez que as declarações podem receber algum tipo de censura, tanto no sentido do que devem incluir quanto no do que devem excluir, podendo ser, portanto, uma representação incompleta dos valores organizacionais. Porém, eles contrapõem à essa dificuldade o fato de que as DV, inclusive na sua possível parcialidade, não deixam de ser um importante fenômeno organizacional, pois o que é incluído e omitido pode ser uma indicação da forma na qual a alta administração deseja que sua organização opere e seja vista operando. Acompanhamos os autores nessa ponderação.

\section{METODOLOGIA}

O exame, de natureza qualitativa, adota sobretudo procedimentos da análise de conteúdo e de discurso, cujas especificações serão apresentadas adiante. Bardin (2011) e Krippendorff (1993) tratam a análise de conteúdo como um conjunto de técnicas de investigação destinadas a formular inferências reproduzíveis e válidas. Assume-se como referência pesquisa internacional, feita em empresas britânicas e norte-americanas (BOURNE, JENKINS e PARRY, 2017).

A análise de conteúdo foi utilizada como primeira aproximação aos textos, servindo para uma primeira descrição do corpus e comparações iniciais com Bourne, Jenkins e Parry (2017). Como elemento auxiliar para essa etapa e construção das categorias de análise, foi utilizado o software Iramuteq. ${ }^{1}$ Os autores recorreram ao Guia Exame de Melhores e Maiores 2017 para identificar as 500 maiores empresas do país, que constituiu o universo de pesquisa. Eles utilizaram a lista da Fortune 500, para as empresas norte-americanas, e da Financial Times Stock Exchange (FTSE List), para as britânicas. Trabalharam, portanto, com um corpus de 3.112 valores em 554 organizações. A presente pesquisa trabalhou com 1.760 valores em 311 organizações - aquelas em que foram encontradas DVs. A opção de trabalhar com as 500 maiores também se justifica pelo fato de não terem sido identificados estudos do gênero na literatura nacional, sendo positiva a apresentação de um estudo com caráter exploratório.

Após a relação, os autores consultaram os sites das empresas, buscando informações sobre a DV na página inicial e em até duas subpáginas - no máximo dois cliques a partir da página

\footnotetext{
O Iramuteq é um software livre, gratuito e com fonte aberta que permite a realização de análises estatísticas sobre corpus textuais. Disponível em: <http://www.iramuteq.org/>. Acesso em: 23 jun. 2020. A pesquisa foi conduzida ao longo do ano de 2018, quando foi feito o processamento no software.
} 
inicial, utilizando os engenhos de pesquisa dos próprios sites, procedimento também utilizado por David e David (2014), no caso relativamente a declarações de missão. Caso não encontrassem uma DV nesse nível, consideravam-na como não existente. Ressalte-se que a explicitação de uma DV com alguma visibilidade é um critério da importância dada pelas empresas às suas DVs, o que é outro elemento a justificar a pesquisa em até duas subpáginas. Também não foram consideradas DV em língua estrangeira, dada a metodologia escolhida - utilização subsidiária da análise de discurso em língua portuguesa.

Seguindo procedimento de Bourne, Jenkins e Parry (2017) foram separados DV descritivas e sintéticas, com apresentação de uma lista de marcadores, formados por uma palavra única ou por um termo composto por duas ou três palavras. As DV descritivas são aquelas redigidas em forma de frase. Os autores argumentam que essas são menos precisas e que seu formato fraseológico requereria um esforço adicional de interpretação, além de prejudicar a consistência do nível de análise. Também seguindo recomendação deles, foram consideradas palavras compostas quando o sentido é claro e o termo é reconhecido pela literatura - como responsabilidade social. Em outros casos, em particular com o emprego do conectivo $e$, foram considerados valores separados - honestidade e integridade foram computados como dois valores. Consideraram-se repetições quando a mesma palavra foi encontrada em mais de uma organização.

A presente pesquisa se diferencia da de Bourne, Jenkins e Parry (2017) a partir desse ponto e com recurso do Iramuteq para fins de análise do corpus de um ponto de vista discursivo, uma vez que as declarações são constructos discursivos per si. O Iramuteq é um software de processamento de análise do discurso e contribuiu para identificação da frequência de termos, relacionamentos entre termos e visualização de clusters terminológicos, conforme será apresentado nos resultados.

Também foi levado em consideração a inexistência de literatura semelhante em língua portuguesa, o que favorece a abordagem mais exploratória adotada pela pesquisa.

\section{Resultados}

\section{Tratamento descritivo}

Foram encontradas 311 DV, o que representa 62,2\% do total. Bourne, Jenkins e Parry (2017) trabalharam com 700 empresas, tendo encontrado DVs em 554 delas, o que representa 79,14\%. Entre as empresas norte-americanas, o percentual foi de $80 \%$; entre as britânicas, $74 \%$ (BOURNE, JENKINS e PARRY, 2017, p. 5).

As DVs brasileiras apresentaram 1.760 valores, o que significa uma média de 5,82 por organização. Bourne, Jenkins e Parry (2017) encontraram uma média geral de 5,6 valores por organização - um pouco abaixo de cinco para as britânicas e de seis para as norte-americanas.

O Quadro 1 apresenta uma comparação entre os valores encontrados pela presente pesquisa e pela de Bourne, Jenkins e Parry (2017). 


\section{QUADRO 1}

\section{Valores ${ }^{2}$}

Valores encontrados somente na pesquisa brasileira (124)

Adaptabilidade, alegria, alta performance, altruísmo, amor, atitude crítica, austeridade, autenticidade, autodesenvolvimento, autonomia, baixo custo, brasilidade, capricho, cidadania, coerência, companheirismo, compartilhamento, competência, competitividade, compromisso, conhecimento, consistência, controle, convicção, cooperação, credibilidade, criação de valor, cuidado, cumplicidade, curiosidade, custo competitivo, dedicação, desempenho, desenvolvimento, desenvolvimento socioeconômico, desprendimento, determinação, diálogo, dignidade, dinamismo, disciplina, disponibilidade, disposição para mudanças, dividir o sucesso, educação, eficácia, empatia, energia, equilíbrio, espiritualidade, estética, faz bem fazer o bem, fazer acontecer, fazer bemfeito, fidelidade, flexibilidade, fortaleza, franqueza, futuro, garra, gente, gestão compartilhada, harmonia, hospitalidade, humanidade, idoneidade, igualdade, imagem, inconformismo construtivo, iniciativa, integração, integralidade, inteligência, intensidade, interdependência, justiça social, liberdade, liberdade de expressão, longevidade, lucratividade, mente aberta, meritocracia, modernidade, não discriminação,

objetividade, orientação ao mercado, ousadia, paranoia produtiva, pensar grande, perpetuidade, perseverança, personalidade, pioneirismo, preocupação, preservação da vida, proatividade, produtividade, regra de ouro, reinvestimento, relacionamento, rentabilidade, reputação, resolutividade, resultados, retribuição, riqueza, segurança no trabalho, sem limites, sempre em movimento, senso de urgência, sinergia; solidariedade, solidez, superação, talento, técnica, time de águias, tradição, união, valorização, verdade, vida, visão e zelo.
Valores encontrados em ambas as pesquisas* (67)

Abertura, accountability, agilidade, ambição, aprendizagem, atitude, atitude otimista, atuação global, clientes, colaboração, compaixão, comprometimento, comunicação, comunidade, confiabilidade, confiança, coragem, crença, crescimento, criatividade, desafio, desenvolvimento das pessoas, diligência, diversão, diversidade, eficiência, empreendedorismo, entusiasmo, equidade, ética, excelência, fazer diferente, democracia, honestidade, humildade, inclusão, inovação, integridade, justiça, lealdade, liderança, meio ambiente, melhoria contínua, orgulho, paixão, parceria, pessoas, profissionalismo, qualidade, qualidade de vida, rapidez, realização, reconhecimento, respeito, responsabilidade, responsabilidade social, responsividade, saúde, segurança, senso de dono, servir, simplicidade, sustentabilidade, tecnologia, trabalho em equipe, transparência e vitória.
Valores encontrados somente na pesquisa norte-americana (14)

Compliance, stakeholders, valor do dinheiro, efetividade, prudência, expertise, esperança, pragmatismo, resiliência, independência, apoio aos outros, empowerment, tenacidade e individualidade.

Fonte: Elaborado pelos autores.

${ }^{2}$ Respeitada a tradução literal. 


\section{Tratamento no Iramuteq}

O tratamento do corpus no Iramuteq gerou a nuvem de palavras retratada na Figura 1.

FIGURA 1

Valores das organizações brasileiras

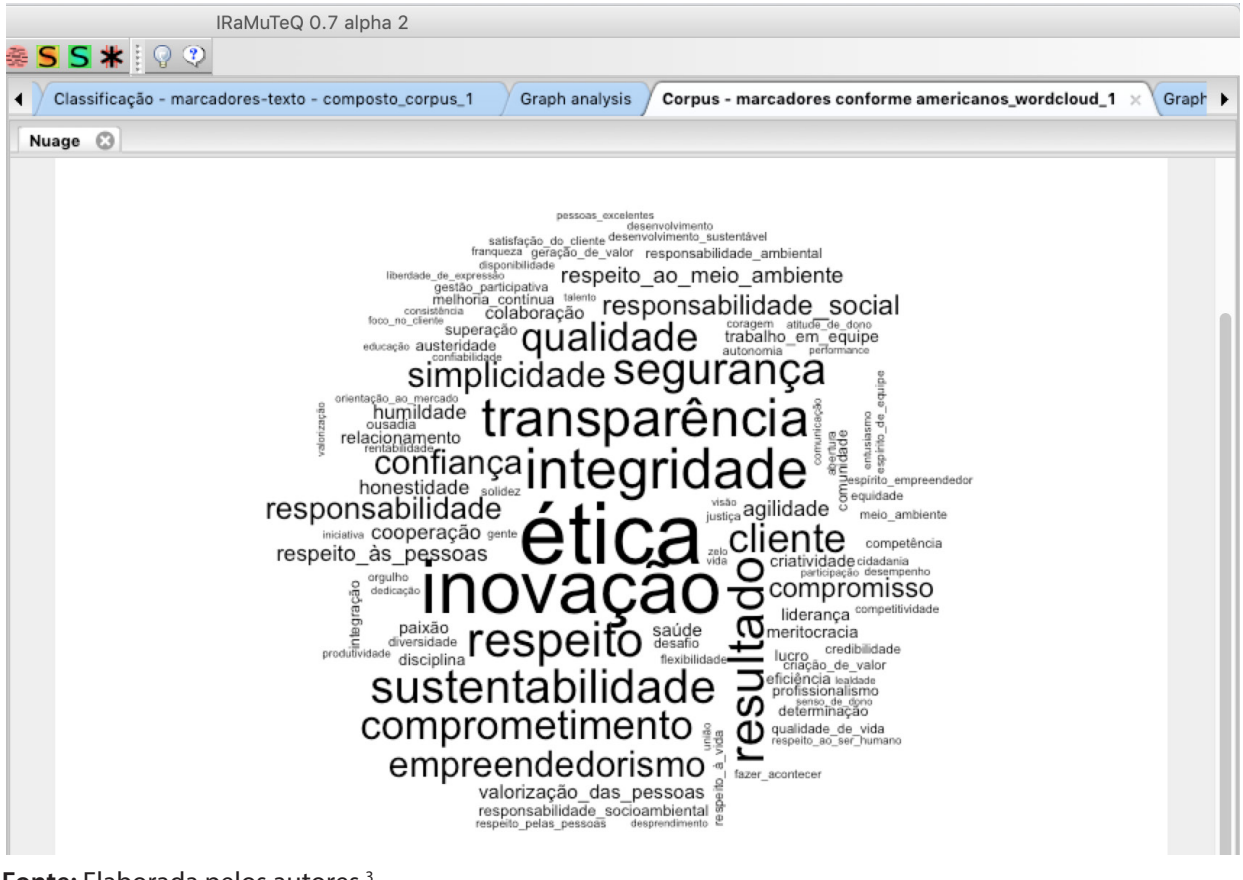

Fonte: Elaborada pelos autores. ${ }^{3}$

A Tabela 1 apresenta os termos que apareceram com mais frequência.

TABELA 1

Valores das organizações brasileiras (frequência dos termos)

\begin{tabular}{|c|c|}
\hline Termo & Quantidade \\
\hline Ética & 114 \\
\hline Inovação & 97 \\
\hline Integridade & 71 \\
\hline Transparência & 66 \\
\hline Resultado & 61 \\
\hline Respeito & 60 \\
\hline Sustentabilidade & 57 \\
\hline Segurança & 54 \\
\hline Comprometimento & 48 \\
\hline
\end{tabular}

\footnotetext{
${ }^{3}$ Com utilização do software Iramuteq.
} 


\begin{tabular}{|c|c|}
\hline Termo & Quantidade \\
\hline Qualidade & 47 \\
\hline Cliente & 47 \\
\hline Empreendedorismo & 41 \\
\hline Simplicidade & 40 \\
\hline Confiança & 38 \\
\hline Responsabilidade & 33 \\
\hline Responsabilidade social & 28 \\
\hline Compromisso & 28 \\
\hline Respeito ao meio ambiente & 20 \\
\hline Respeito às pessoas & 20 \\
\hline
\end{tabular}

Fonte: Elaborada pelos autores com uso do Iramuteq.

Com base nesses resultados, o Iramuteq gerou a rede de palavras apresentada pela Figura 2.

FIGURA 2

Valores das organizações brasileiras (configuração em rede dos clusters terminológicos)

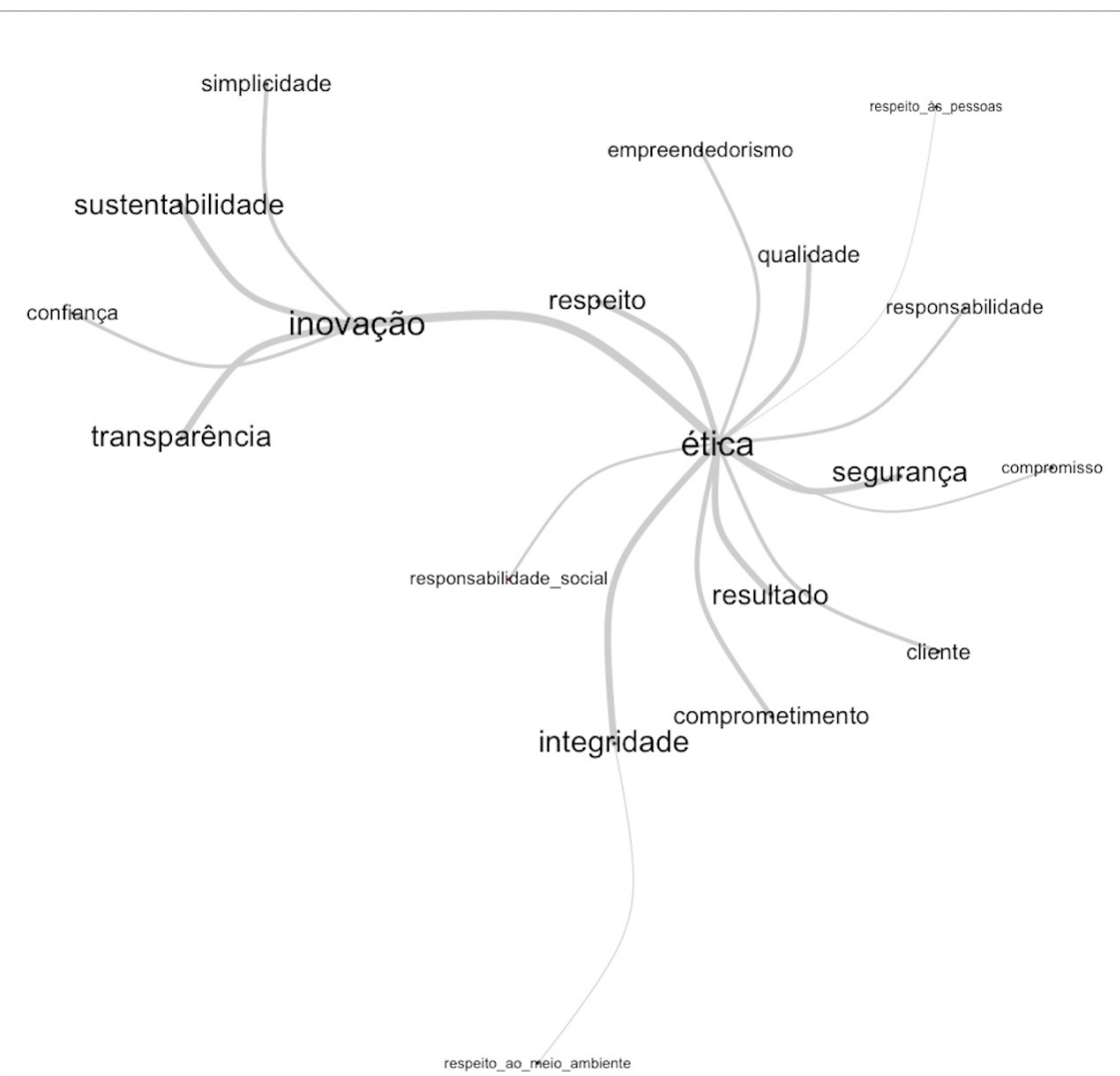

Fonte: Elaborada pelos autores. ${ }^{4}$ 


\section{Discussão}

Os resultados quantitativos são ambíguos. Trata-se de um percentual expressivo de empresas que presentam uma DV (62,2\%). No entanto, diante do fato de ser assunto explorado pela literatura há mais de três décadas, poderia se esperar uma quantidade ainda maior. Ademais, o universo abrange as 500 maiores empresas nacionais, o que também gera uma expectativa de maior presença de DV. Isso também se evidencia quando comparado com os resultados internacionais - 79,14\% de empresas apresentavam uma DV.

As DV brasileiras apresentaram 1.760 valores, o que significa uma média de 5,82 por organização. Bourne, Jenkins e Parry (2017) encontraram um total de 3.112 valores, com média geral de 5,6 valores por organização - um pouco abaixo de cinco para as britânicas e de seis para as norte-americanas. Pode-se compreender a quantidade maior de valores em Bourne, Jenkins e Parry (2017) como associada ao tamanho do corpus - 554 organizações, diante de 311 organizações na pesquisa nacional (243 empresas a mais, com uma média de 5 valores por empresa, já representariam 1.215 valores a mais).

Era esperado não encontrar uma quantidade muito grande de valores por empresa, uma vez que, se tudo é valor, nada é valor - a multiplicação excessiva esvazia o significado e a força dos valores, assim como ocorre com o abuso no emprego de um termo. $\mathrm{O}$ achado confirma essa perspectiva, com a moda 5 representando um valor adequado de valores. A proximidade com a média internacional também demonstra que a situação é adequada.

Eliminadas as repetições e depurando os valores, seguindo procedimento de classificação intersubjetiva proposto por Bourne, Jenkins e Parry (2017) chegou-se a uma quantidade de 191 valores apresentados pelas empresas brasileiras, em face de 81 apresentados por eles. Calculou-se a taxa de repetição como total de valores por valores depurados, chegando-se a uma taxa de 9,21 no caso brasileiro e 38,41 no caso da pesquisa internacional. Ou seja, a rigor, um valor encontrado nas empresas brasileiras se repetiu em cerca de nove delas, ao passo que um valor encontrado nas empresas da pesquisa internacional se repetiu em cerca de 38,41 . Essa taxa de repetição cerca de quatro vezes superior na pesquisa internacional pode demonstrar maior coerência no conjunto das empresas da pesquisa internacional, como práticas de benchmarking mais intensas, ou maior sedimentação da literatura sobre o assunto junto às empresas, fatores não explorados por Bourne, Jenkins e Parry (2017).

O processo de depuração na presente pesquisa resultou em 191 valores, ao passo que o de Bourne, Jenkins e Parry (2017) em 81. O fato de as empresas brasileiras apresentarem quase o dobro de valores em relação às internacionais é outro elemento a requerer pesquisas adicionais que possam compreender a causa dessa maior criatividade nacional. Não é possível, com base só nos achados da presente pesquisa, eliminar a ambiguidade de origem dos resultados, ou seja, identificar, por exemplo, se eles se devem somente a diferenças culturais entre os países ou entre estilos de gestão. Também não foi feita, na presente pesquisa, uma análise baseada na propriedade das empresas, o que abre outra vertente para análises futuras. ${ }^{5}$

\footnotetext{
${ }^{5} \mathrm{O}$ fato de uma empresa ter propriedade estrangeira pode fazer com que seus valores espelhem os da matriz, o que pode ser uma influência nos resultados encontrados.
} 
Há uma taxa de coincidência - valores encontrados nas pesquisas internacional e brasileira, respectivamente - de 32,7\%, baixa o bastante para indicar que, embora a elaboração de DVs como instrumento de gestão tenha se disseminado para a cultura empresarial nacional - dada a presença de DV em 62,2\% das empresas -, os valores em si não são universalizáveis. Apesar de ser um elemento que também aponta para a necessidade de pesquisas adicionais, esse achado condiz com a perspectiva de apropriação da literatura internacional por parte da literatura e da prática nacional. Wood Junior, Tonelli e Cooke (2011) analisaram o assunto do ponto de vista da literatura de recursos humanos, demonstrando como houve períodos de colonização, neocolonização e pós-colonização, com o desenvolvimento de abordagens genuinamente brasileiras.

Os termos mais frequentes delimitam dois grandes campos semânticos, em torno dos termos "ética” e "inovação", conforme apresentado na Figura 2. A preocupação com a ética - ética (114), integridade (71), transparência (66), respeito (61), responsabilidade (33) e compromisso (28) - revela uma disposição à adoção de comportamentos moralmente aceitáveis, seja no âmbito interno, seja no externo. Não obstante sua amplitude semântica, sobretudo no campo filosófico, o termo "ética" costuma se referir a um dever ser adequado, em sintonia com o conceito metafísico do bem. Integridade se refere à qualidade do que é inteiro, ou seja, o comportamento único e autêntico, focado num só interesse, que é alcançar aquele dever ser estipulado pela ética - para ser ético é preciso ser íntegro. Transparência remete à ausência de interesses ou práticas ocultas - quando se é ético e íntegro, não há nada a esconder. Respeito (deferência, consideração), responsabilidade (responder por algo) e compromisso (acordo, promessas mútuas) articulam um segundo subcampo conectado ao termo "ética", mais afeito às práticas relacionais das empresas em relação aos seus diferentes públicos.

O segundo grande campo vem capitaneado pelo termo "inovação". De fato, inovação virou palavra de ordem na literatura especializada sobre gestão. "Inove ou morra" virou lema diante da alta competitividade, do aumento das expectativas dos clientes e do ritmo frenético de mudanças vivenciado pela sociedade em geral. Autores clássicos, como Peter Drucker, contribuíram para reforçar a inovação como algo inerentemente importante para as empresas:

[a organização moderna] precisa estar organizada para abandonar sistematicamente aquilo que estiver estabelecido, habitual, familiar e cômodo, quer isso signifique um produto, um serviço ou um processo; um conjunto de habilidades; relações humanas e sociais; ou a organização em si. Em suma, ela precisa estar organizada para uma mudança constante (DRUCKER, 2002, p. 34).

Percebe-se, portanto, que as empresas aderem, discursivamente, a um comportamento moralmente aceitável - seu resultado virá de forma legal, legítima e justa - e ao desafio de repensarem seus produtos e serviços, com vistas à sua substituição por produtos e serviços inovadores, capazes de lhes assegurar a sobrevivência num ambiente muito competitivo. 


\section{CONCLUSÃO}

As DV são um elemento importante no perfil identitário das empresas porque são formulações discursivas explícitas de orientação comportamental - sinalizam os comportamentos aceitos e incentivados. Como tal, os valores são importante referência para a compreensão do comportamento das organizações e das pessoas que as integram.

Apesar da ampla difusão do tema na literatura especializada, somente 62,2\% das 500 maiores empresas brasileiras apresentam uma DV em sua página na internet. Em se tratando das maiores empresas nacionais, reforça-se a sensação de que esse número deveria ser maior, bem como a comparação com experiências internacionais - $80 \%$ nas empresas norte-americanas e $74 \%$ entre as britânicas. A iniciativa de pesquisar o assunto e realizar esse inventário levantamento censitário junto às 500 maiores empresas nacionais - traz uma contribuição importante ao apresentar um panorama dessa autoimagem das empresas brasileiras em termos de valores. Com base nesse panorama, temos uma perspectiva de como as companhias nacionais se enxergam em termos valorativos, o que, além de um elemento em si importante - haja vista a crescente preocupação acadêmica com o tema "propósito" em empresas -, possibilita que sejam desenhados novos percursos de pesquisa.

As empresas brasileiras revelaram uma criatividade muito maior na definição de valores do que suas contrapartes internacionais. Esse achado descortina um campo de investigação próprio, que pode encontrar um diferencial valorativo peculiar ao empreendedor e ao gestor brasileiro. Caso confirmado, seria mais um elemento a demonstrar o processo de "apropriação com transformação" apontado por Wood Junior, Tonelli e Cooke (2011).

De um ponto de vista dos resultados da análise de conteúdo, a pesquisa possibilitou identificar que os dois campos semânticos principais, em torno dos quais os valores se articulam, são os da ética e o da inovação. Considerando que as DVs, conforme apontado pela discussão teórica, sinalizam a forma como as empresas desejam ser percebidas pelos públicos externos e os comportamentos aceitáveis que esperam de seus públicos internos, é bastante significativo que esses sejam os dois campos encontrados. Em termos de seu perfil identitário, constatado pelos valores que professam explicitamente, temos que as empresas nacionais desejam ser compreendidas como éticas e inovadoras.

No que concerne à agregação dos valores, foi possível identificar pela pesquisa que as maiores empresas brasileiras estão preocupadas com ética e inovação. Passados sucessivos escândalos de corrupção envolvendo empresas do país, é benfazejo verificar que, ao menos do ponto de vista discursivo-normativo, as companhias nacionais buscam um comportamento ético. Mesmo diante de notórias dificuldades - como complexidade regulatória, emaranhado de impostos, políticas públicas discricionárias e fracamente articuladas etc. -, as empresas compreendem a inovação como o caminho para a sobrevivência.

A pesquisa traz a discussão para o ambiente empresarial brasileiro e para DV elaboradas em português. Abre espaço para pesquisas posteriores que possam explorar, por exemplo, a aderência das pessoas aos valores organizacionais ou aprofundar a análise quanto à especificidade das empresas nacionais com relação à formulação de suas declarações de valores. 


\section{REFERÊNCIAS}

AGLE, B. R.; CALDWELL, C. B. Understanding research on values in business: a level of analysis framework. Business \& Society, v. 38, n. 3, p. 326-387, set. 1999.

AMIS, J.; SLACK, T.; HININGS, C. R. Values and organizational change. The Journal of Applied Behavioral Science, v. 38, n. 4, p. 436-465, dez. 2002.

BANSAL, P. From issues to actions: the importance of individual concerns and organizational values in responding to natural environmental issues. Organization Science, v. 14. n. 5, p. 510-527, 2003.

BARDIN, L. Análise de conteúdo. São Paulo: Edições 70, 2011.

BARTUNEK, J. M. Changing interpretative schemes and organizational restructuring: the example of a religious order. Administrative Science Quarterly, n. 29, p. 355-372, 1984.

BAUM, J. A. C.; OLIVER, C. (1991). Institutional linkages and organizational mortality. Administrative Science Quarterly, n. 36, p. 187-218, 1991.

BOURNE, H.; JENKINS, M.; PARRY, E. Mapping espoused organizational values. Journal of Business Ethics, v. 159, p. 133-148, nov. 2017.

BURNES, B.; JACKSON, P. Success and failure in organizational change: an exploration of the role of values. Journal of Change Management, v. 1, n. 2, p. 133-162, 2011.

CARLISLE, Y.; BADEN-FULLER, C. Re-applying beliefs: an analysis of change in the oil industry. Organizational Studies, v. 25, n. 6, p. 987-1019, 2004.

CHA, S. E.; EDMONDSON, A. C. When values backfire: leadership, attribution, and disenchantement in a value-driven organization. Leadership Quarterly, n. 17, p. 57-78, 2006.

DAVID, M. E.; DAVID, F. R. Mission statement theory and practice: a content analysis and new direction. International Journal of Business, Marketing, and Decision Sciences, v. 7, n. 1, p. 95-110, 2014.

DEAL, T; KENNEDY, A. Corporate cultures: the rites and rituals of corporate life. Reading: AddisonWesley, 1982.

DICKSON, M. W. et al. Ethical climate: the result of interactions between leadership, leader, values and follower values'. Leadership Quarterly, n. 12, p. 1-21, 2001.

DRUCKER, P. F. O melhor de Peter Drucker: obra completa. São Paulo: Nobel, 2002.

ENGLAND, G.; LEE, R. The relationship between managerial values and manaferial success in the United States, Japan, India, and Australia. Journal of Applied Psychology, n. 59, p. 411-419, 1974.

ENZ, C. The relationship between organization valuesharing and influence over strategic decisions. International Journal of Values-Based Management, n. 2, p. 79-91, 1989.

ETZIONI, A. A comparative analysis of complex organizations: on power, involvement and their correlates. Nova York: The Free Press of Glencoe, 1961.

GRØGAARD, B; COLMAN, H. L. Interpretative frames as the organization's mirror: from espoused values to social integration in MNEs. Management International Review, v. 56, n. 2, p. 171-194, 2016.

GROJEAN, M. W. et al. Leaders, values, and organizational climate: examining leadership strategies for establishing an organizational climate regarding ethics. Journal of Business Ethics, n. 55, p. 223-241, 2004. 
HABERMAS, J. Direito e democracia: entre facticidade e validade. V. II. Rio de Janeiro: Tempo Brasileiro, 2003.

HAMBRICK, D.; BRANDON, G. Executive values. In: HAMBRICK, D. (Ed.). The executive effect: concepts and methods for studying top managers. Greenwich: JAI, 1988. p. 3-34.

HOFSTEDE, G. Nationality and espoused values of managers. Journal of Applied Psychology, n. 61, p. 148-155, 1976.

HOFSTEDE, G. Cultures and organizations: software of the mind. Nova York: McGraw-Hill, 1997.

HOWELL, A.; KIRK-BROWN, A.; COOPER, B. K. Does congruence between espoused and enacted organizational values predict affective commitment in Australian organizations? The International Journal of Human Resource Management, v. 23, n. 4, p. 731-747, 2012.

JONSEN, K. et al. Evaluating espoused values: does articulating values pay off? European Management Journal, v. 33, n. 5, p. 332-340, 2015.

KAPLAN, A.; LASSWELL, H. Poder e sociedade. Brasília, DF: Editora UnB, 1979.

KELSEN, H. Teoria pura do direito. São Paulo: Martins Fontes, 1987.

KRIPPENDORFF, K. Metodología de análisis de contenido: Teoria y Práctica. Barcelona: Piados Comunicación, 1993.

LEE, C. Ethic training: facing the tough questions. Training, n. 23, p. 30-34, 1986.

LIEDTKA, J. Organizational value contention and managerial mindsets. Journal of Business Ethics, n. 10, p. 543-557, 1991.

MEYER, J.; ROWAN, B. Institutional organizations: formal structure as myth and ceremony. American Journal of Sociology, n. 83, p. 340-363, 1977.

MEYERSON, D.; MARTIN, J. Cultural change: an integration of three different views. Journal of Management Studies, n. 24, p. 623-647, 1987.

MORGAN, G. Imagens da organização. São Paulo: Atlas, 1996.

NAGEL, T. Visão a partir de lugar nenhum. São Paulo: Martins Fontes, 2004.

NOHRIA, N.; GHOSHAL, S. Differentiated fit and shared values: alternatives for managing headquarterssubsidiary relations. Strategic Management Journal, n. 15, p. 491-502, 1994.

PETERS, T.; WATERMAN JUNIOR, R. In search of excellence: lessons from America's best run companies. New York: Harper \& Row, 1982.

PETTIGREW, A. Context and action in the transformation of the firm. Journal of Management Studies, n. 24, p. 649-670, 1987.

POSNER, B. Z.; SCHMIDT, W. H. Values and the American manager: an update updated. California Management Review, v. 34, n. 3, p. 80-94, 1992.

RANSON, S.; HININGS, C. R.; GREENWOOD, R. The structuring of organizational structures. Administrative Science Quarterly, n. 25, p. 1-17, 1980. 
RAPOPORT, A. Lutas, jogos e debates. Brasília, DF: Editora UnB, 1980.

SCHEIN, E. H. Organizational culture and leadership. San Francisco: Jossey-Bass, 1985.

SCHNEIDER, B. Organizational climates: an essay. Personnel Psychology, n. 28, p. 447-479, 1975.

SELZNIK, P. TVA and the grass roots. Berkeley: University of California Press, 1949.

STADLER, C.; HINTERHUBER, H. H. Shell, Siemens and Daimler-Chrysler: leading change in companies with strong values. Long Range Planning, v. 38, n. 5, p. 467-484, 2005.

VICTOR, B.; CULLEN, J. B. A theory and measure of ethical climate in organizations. Research in Corporate Social Performance and Policy, n. 9, p. 51-71, 1987.

WOOD JUNIOR, T.; TONELLI, M. J.; COOKE, B. Colonização e neocolonização da gestão de recursos humanos no Brasil (1950-2010). Revista de Administração de Empresas, São Paulo, v. 51, n. 3, p. 232243, maio/jun. 2011.

ZANDER, L.; JONSEN, K.; MOCKAITIS, A. I. Leveraging values in global organizations: premises, paradoxes and progress. Management International Review, v. 56, n. 2, p. 149-169, 2016.

\section{ANDRÉ REHBEIN SATHLER}

ORCID: https://orcid.org/0000-0003-1856-9839

Doutor em Filosofia pela Universidade Federal de São Carlos (UFSCar); Professor do Mestrado Profissional em Gestão Estratégica das Organizações no Centro Universitário IESB, Brasília - DF, Brasil.

E-mail: andre.sathler@gmail.com

\section{ROBERTO CAMPOS ROCHA MIRANDA}

ORCID: https://orcid.org/0000-0003-2294-286X

Doutor em Ciência da Informação (UnB); Analista Legislativo- Recursos Humanos- na Câmara dos Deputados; Professor do Mestrado Profissional em Poder Legislativo no CEFOR/Câmara dos Deputados, Brasília - DF, Brasil.

E-mail: roberto.rocha@camara.leg.br

\section{MURILO DE ASSIS SILVA}

OCRID: https://orcid.org/0000-0002-0281-9787

Mestre em Gestão Estratégica de Organizações pelo Instituto de Educação Superior de Brasília (IESB); Professor do Curso de Tecnologia em Análise e Desenvolvimento de Sistemas do Instituto Federal de Goiás (IFG) -

Câmpus Jataí, Brasília - DF, Brasil. E-mail: murilo.assis@ifg.edu.br 